\title{
The Origin of the Improvement of Dielectric Property in the Modulated Structures: Electronic Structure Study
}

\author{
J. D. Kim, K. S. Choi, Y. S. Yang," and D. Jung" \\ Deparment of Chemistry and histitue of Natural Basic Science, Wonkwang University, Iksan, Jeonbuk 570-749. Korea \\ "E-mail: djungawonkw'ang.ac:kr \\ ${ }^{\dagger}$ Department of Advanced Materials Engineering, Woosuk University, Wanju, Jeonbuk 565-701. Korea \\ Recived September 14.2004
}

Key Words : Dielectric property, Modulated structure, Ferroelectric

Some group of erystals possess the unusual characteristics of being permanently polarized within a given temperature range. Unlike the general piezoelectric classes, which produce a polarization under stress, the pyroelectrics develop this polarization spontaneously and form permanent dipoles in the structure. This polarization also changes with temperatureshence the term pyroelectricity comes. Pyroelectric crystals such as tourmaline and wurtzite are often called polar materials, referring to the unique polar axis existing within the lattice. The length of the polar axis (dipole moment) varies with temperature, changing sign as the temperature is either elevated or lowered. A subgroup of the spontaneously polarized pyroelectrics is a special category of materials known as ferroelectrics. Materials in this group are characterized as crystals that possess a spontaneous dipole, and this dipole is reversible by an electric field of some magnitude less than the electric breakdown of the material itself. Because of the empirical nature of determining the reversibility of the dipoles, as detected in a hysteresis loop measurement, one cannot predict the existence of ferroelectricity in a new material with much accuracy. We do see, however, that the basis for the existence of ferroelectricity rests primarily on structural (symmetrical) considerations.

Generally, the dielectric constants of ferroelectric materials are hundreds times bigger than those of normal dielectric compounds. It is necessary to possess stronger dielectric properties when a material is applied for the phase shifters, tunable filters, capacitors, non-volatile ferroelectric random access memory (FeRAM) devices, dynamic random access memory (DRAM) devices and steerable antemas. Many scientists, therefore, have tried to increase the dielectric property of ferroelectric materials by substituting the preexisting metals with various transition metals, and/or by changing the synthetic processes. Several compounds. for example, lead zirconate titanates $\left[\mathrm{Pb}\left(\mathrm{Ti}_{1-\mathrm{x}}, \mathrm{r}_{\mathrm{x}}\right) \mathrm{O}_{3}, \mathrm{P} 7 \mathrm{~T}\right]^{1}$ and lead lanthanum zirconate titanates $\left[\left(\mathrm{Pb}_{L_{-y} \mathrm{~L}} \mathrm{La}_{\mathrm{y}}\right)\left(\mathrm{Ti}_{1-\mathrm{X}} \mathrm{Zr}_{\mathrm{r}}\right) \mathrm{O}_{\mathrm{s}}\right.$. PLZTT ${ }^{2}$ have been successfully developed through the substitutional method. Both compounds exhibit better dielectric property than the intrinsic $\mathrm{PbTiO}_{3}$ does. In addition, a flood of research have been focused on the syntheses of new materials which are exhibiting high dielectric constants. Aurivillius phase compounds such as $\mathrm{SrBi}_{2} \mathrm{Ta}_{2} \mathrm{O}_{9}(\mathrm{SBT})$ and $\mathrm{SrBi}_{2} \mathrm{Nb}_{2} \mathrm{O}_{2}(\mathrm{SBN})$ are the typical examples. ${ }^{3-6}$

Differently from the substituted solution form mentioned above, the modulated structure form (see Figure 1) with two kinds of classical ferroelectric compounds in film type can be introduced. Modulated structure framework is an artificial crystal which is designed to deposit the alternating layers with more than two different materials. A ferroelectric perovskite is deposited onto a substrate first time and then the second compound is deposited onto the surface of the first one, and again the first one onto the surface of the second one, and so on. The modulated structure film is known to exhibit better physical properties compared to the individual materials. ${ }^{7-8}$ For example, ferroelectric modulated structure which is made of $\mathrm{BaTiO}_{5}$ and $\mathrm{SrTiO}_{3}$ shows higher voltage tunability and dielectric properties than $\mathrm{BaTiO}_{3}$ only or $\mathrm{SrTiO}_{3}$ only. ${ }^{\mathrm{O}-1}$ ?

Dielectric property of a material depends on the amount of structural distortions in the compounds. Withers and coworkers have suggested that the major cause of spontaneous polarization in the two-layer of $\mathrm{ABO}_{3}$ materials is the displacement of the A site cation in the perovskite block along the a-direction in the polar space group $\mathrm{A} 2{ }_{1} \mathrm{am} . .^{1+-17}$ In addition, the distorted $\mathrm{O}-\mathrm{B}-\mathrm{O}$ chains which construct perovskite layers, are thought to be the origin of the polarization in the $\mathrm{ABO}_{3}$ perovskites. "So the higher polarization is expected when the structural distortion is stronger.

In the deposition of yttrium barium copper oxide (YBCO) films onto $\mathrm{MgO}$ substrates, it has been observed that the

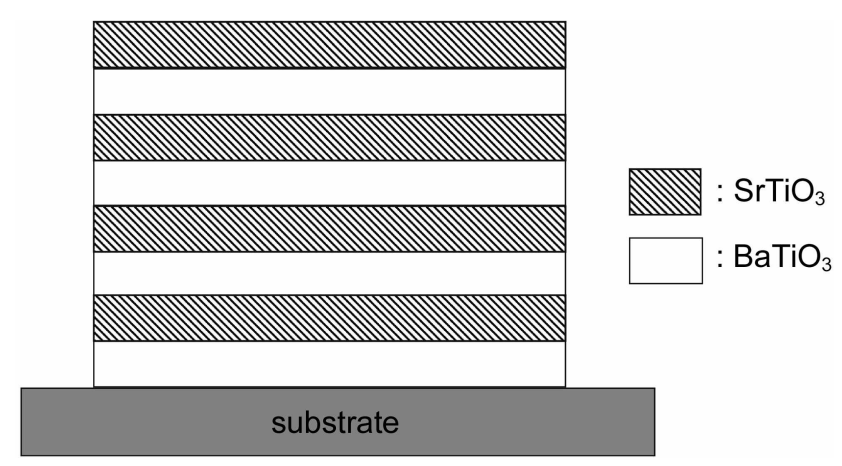

Figure 1, The simple view ol the modulated structure system made of Srlio, and Bailio. 
nature of the substrate surface can influence the structure of the deposited film.18 The deposited film nucleated in the island form, indication that there is significant lattice mismatch between the film and the substrate. The strain of this misinatch is relieved by the introduction of misfit dislocations. Ge film deposited onto Si surface also show similar behavior that the film forms in the cluster form. typically after 1-5 monolayers have been deposited. ${ }^{14)}$ As a consequence, structural distortion is essentially formed when a material is deposited onto the surface of a different compound. The modulated structure made by laser ablation methd with $\mathrm{Sr}^{2} \mathrm{iOO}_{3} / \mathrm{BaTiO}_{3}$ cannot be exceptional. The lattice parameters of $\mathrm{Sr}^{-1 i O}$ and $\mathrm{BaTiO}_{3}$ are 3.9051 $\overline{\mathrm{A}}$ and $3.9947 \AA$, respectively. The difference of their lattice parameter by about $0.1 \AA$ causes the structural distortion when they are deposited alternatively, and the structural strain will increase as the film thickness is increased. It is expected structurally, therefore, that the dielectric constant of the modulated structure made of $\mathrm{Sr}^{\prime} \mathrm{IiO}_{3} / \mathrm{BaTiO}_{3}$ may be higher than the intrinsic $\mathrm{Sr}^{-} \mathrm{IiO}_{3}$ only or $\mathrm{BaTiO}_{3}$ only, It is necessary, therefore, to investigate the reason why the structural distortion causes the improved dielectric property. In this communication, the fundamental investigations on the origin of the polarization in $\mathrm{Ba}^{\prime} \mathrm{iO}_{3} / \mathrm{SrTiO}_{3}$ modulated system will be presented by examining the electronic structure of the system.

\section{Electronic Structure Calculations}

Band calculation based on the given structure is a good method to examine the electronic structure of a material. In the deposited film, it is impossible to know the exact distorted structure. It has been well known that the central metal atom in a ferroelectric material moves toward oxygen by $0.1 \AA$ when electric field is applied, thereby generating the structural distortion. We suggest three distorted model
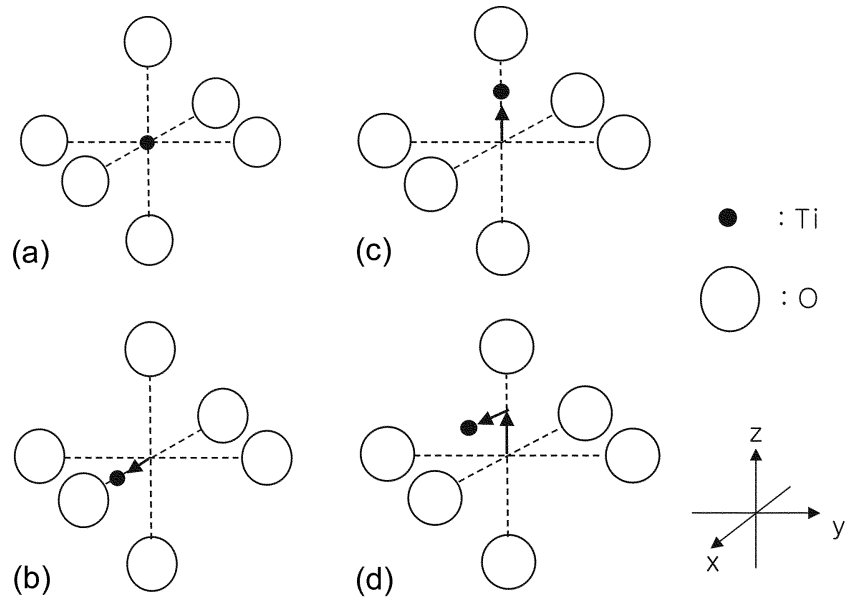

Figure 2. The model structures of ' $\mathrm{IiO}_{0}$ octahdra: (a) undistorted, (b) the displacement of the central metal atom along the $\mathrm{x}$-axis by $0.2 \AA$. (c) the displacement of the central metal atom along the 7. axis by $0.2 \lambda$, (d) the displacement of the central metal atom along the $z$-axis by $0.2 X$ and additional movement along the $x$-inis by 0.2 A.
Table 1. Ntomic Parameters used in I:F ITP Calculationsa : Valence orbital Jonization Potential $\mathrm{H}_{\mathrm{i}}(\mathrm{cV})$ and Exponent of the Slater-type Orbital $\zeta$

\begin{tabular}{ccclc}
\hline atom & orbital & $\mathrm{I}_{\mathrm{i}}$ & \multicolumn{1}{c}{$\zeta_{1}\left(\mathrm{c}_{1}\right)$} & $\zeta_{-}\left(\mathrm{c}_{2}\right)$ \\
\hline $\mathrm{Ti}$ & $3 \mathrm{~d}$ & -11.70 & $4.67(0.3646)$ & $1.986(0.7556)$ \\
& $4 \mathrm{~s}$ & -5.93 & 1.20 & \\
& $4 \mathrm{p}$ & -4.11 & 1.20 & \\
$\mathrm{O}$ & $2 \mathrm{~s}$ & -32.3 & 2.275 & \\
& $2 \mathrm{p}$ & -14.8 & 2.275 & \\
\hline
\end{tabular}

a : Parameters are collected firom the following data: (a) clementi. $\Gamma$..: Raselti. C. Afomic Data Aictear Data Tahles 1974. 14. 177. (b) McLeen. A. D.: McLeet. R. S. Atomic Dator Aucted Lata lables 1981. 26. 197. (c) Richardson. J, W.: Blackmat. M. J.: Ranochak. J. Г., J. Chent. Phs. 1073, 58,3010 .

structures of $\mathrm{Sr}^{2}\left[\mathrm{O}_{3}\right.$ ( $\mathrm{BaTiO}_{3}$ ) film deposited onto $\mathrm{BaTiO}_{3}$ $\left(\mathrm{SrTiO}_{3}\right)$ surface according to the fact that the metal ion in the octahedral center moves to $x$ - and $z$-directions by $0.2 \AA$. which are shown in Figures 2(b) and 2(c), respectively. In addition, one more model structure that the central metal ion moves to z-direction by $0.2 \AA$ and additionally moves to $\mathrm{x}$ direction by $0.2 \AA$, are shown in Figures 2 (d). Here the movement of $0.2 \AA$ comes from the summation of the original displacement of $0.1 \AA$ and the distortion arisen because of the lattice mismatch between $\mathrm{BaIiO}_{3}$ and $\mathrm{SrTiO}_{3}$. Undistorted perovskite structure of $\mathrm{Sr}^{\prime} \mathrm{liO}_{3}\left(\mathrm{BaTiO}_{3}\right)$ is given
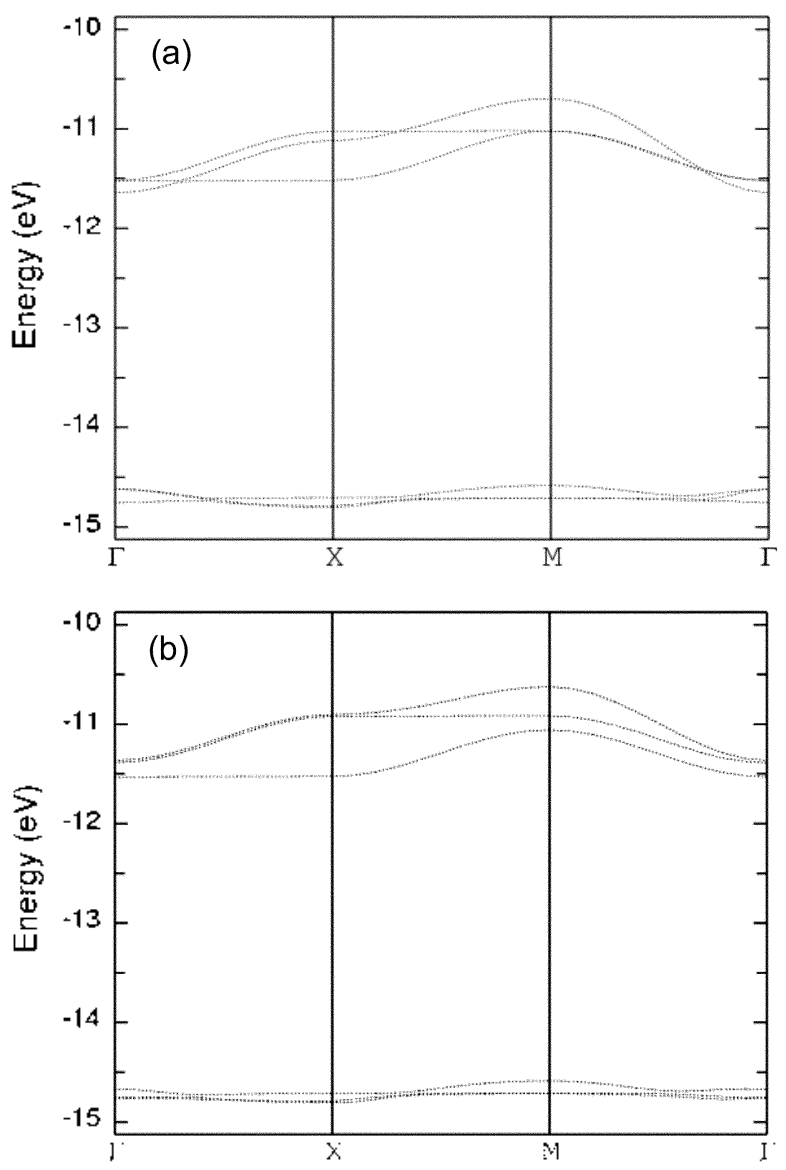

Figure 3. Band dispersion relations calculated for $\mathrm{BaTiO}_{3}$ with the model structures of (a) Figure 2(a). (b) Figure 2(b). 

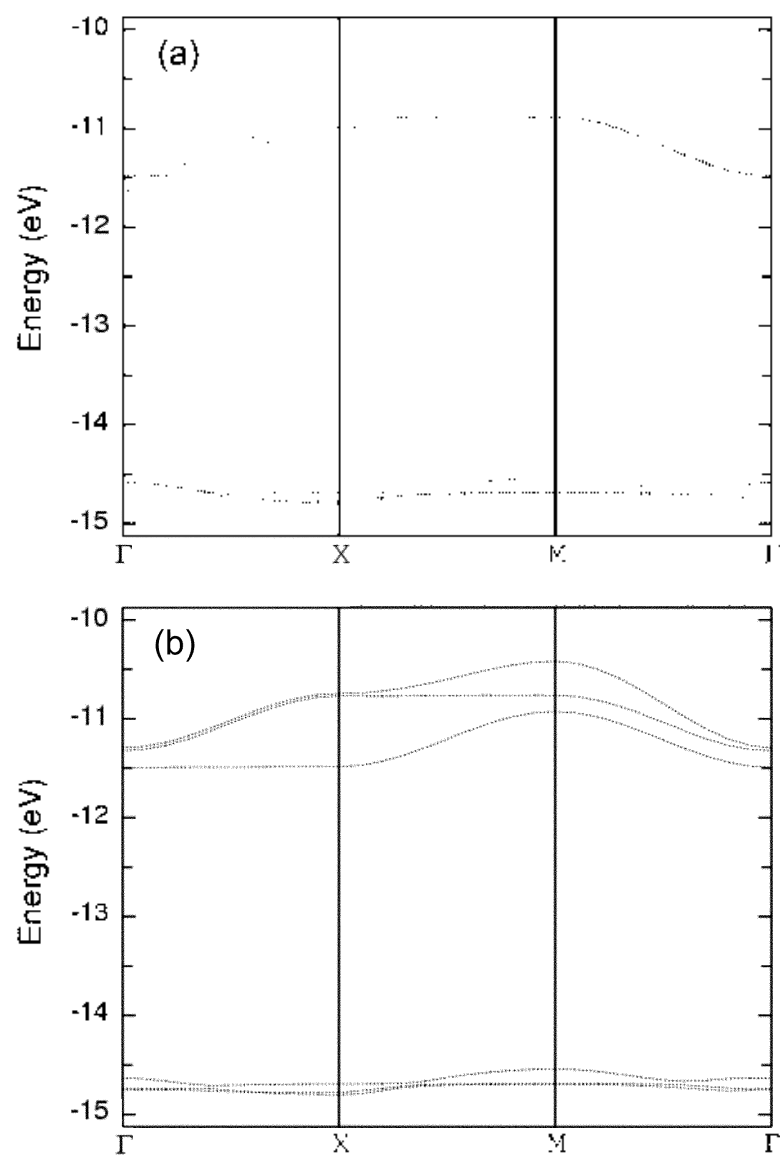

Figure 4. Band dispersion relations calculated for $\mathrm{SrTiO}_{3}$ with the model structures of (a) Figure 2(a). (b) Figure 2(b).

in Figure 2(a). Band disperions of $\mathrm{SrTiO}_{3}\left(\mathrm{BaTiO}_{3}\right)$ is examined by adopting the tight-binding calculation based on the extended Huckel method. ${ }^{?-2}-21$ The atomic parameters used in the calculation are given in Table 1.

Band dispersion curves calculated for undistorted and distorted model structures of $\mathrm{Ba}^{\prime} \mathrm{iO}_{3}$ with the forms of 2(a) and 2 (b) are shown in Figures 3 (a) and $3(b)$, and those of Srlio; in figures $4(a)$ and $4(b)$, respectively. Band structures calculated for the form of 2(c) and 2(d) are similar to that of 2 (b), so are not shown. Out of two subband groups in each figure the single dispersion curve around $-11.5 \mathrm{eV}$ represents the conduction band, and the other subband group containing three dispersion curves around $-14.5 \mathrm{eV}$ represents the valence band.

The valence band is made up of largely the oxygen pcharacter, while the conduction band is made up of largely the titanium d-character. Of course, titanium d-orbital and oxygen p-orbital weakly contribute to the valence band and conduction band, respectively. The band widths of conduction and valence bands for undistorted $\mathrm{Sr}^{\prime} \mathrm{iO}_{3}$ are $0.745 \mathrm{eV}$ and $0.294 \mathrm{eV}$, and those for $\mathrm{Ba}^{\prime} \mathrm{IIO}_{3}$ are $0.620 \mathrm{eV}$ and $0.216 \mathrm{eV}$, respectively. In the distorted $\mathrm{Sr}^{\prime} \mathrm{IiO}_{\hat{1}}$, the widths of conduction bands are ranged from 0.451 to 0.584 $\mathrm{eV}$, and those of valence band are ranged from 0.216 to $0.293 \mathrm{eV}$ depending upon the distortion. The band widths of the distorted structures are smaller than those of the
Table 2. The bandwidths of conduction and valence bands of ditierent structures

\begin{tabular}{ccccc}
\hline \multirow{2}{*}{ Structures } & \multicolumn{2}{c}{$\begin{array}{c}\text { Valence Band Width } \\
\text { (eV) }\end{array}$} & \multicolumn{2}{c}{$\begin{array}{c}\text { Conduction Band Width } \\
\text { (eV) }\end{array}$} \\
\cline { 2 - 5 } & Balio, & SrliO, $_{3}$ & BaTiO; & SrliO $_{3}$ \\
\hline 2(a) & 0.216 & 0.294 & 0.620 & 0.745 \\
2(b) & 0.215 & 0.293 & 0.470 & 0.570 \\
2(c) & 0.161 & 0.216 & 0.491 & 0.584 \\
2(d) & 0.192 & 0.255 & 0.388 & 0.451 \\
\hline
\end{tabular}

undistorted structure. Similar trend can be found in Ba'liO; whose data are given in Table 2 . It is noticed from the data that the more distorted structure shows smaller band width. This means that the interactions between the oxygen $\mathrm{p}$ orbitals and the titanium d-orbitals are weaker in distorted structures even though some $\mathrm{Ii}-\mathrm{O}$ bond lengths become shorter in distorted structures because of the dislocation of the metal toward oxygen. Band gaps of undistorted $\mathrm{Sr}^{3} \mathrm{liO}$; and $\mathrm{BaTiO}_{3}$ are $2.9365 \mathrm{eV}$ and $2.941 \mathrm{eV}$, respectively. Those of distorted $\mathrm{Sr}^{\circ} \mathrm{liO}$, and $\mathrm{BaTiO}_{\mathrm{s}}$ in Figure $2(\mathrm{~b})$ are $3.0754 \mathrm{eV}$, and $3.063 \mathrm{eV}$, respectively. Although not shown, the band gap increases with the magnitude of distortion. Electrons can move through the orbital-orbital interaction channel. Generally, a weak orbital mixing provides a worse condition for the electrons to travel throughout the bonding area. thereby generating the localized situation. In addition, the larger band gap found in the distorted structures creates the more localized situation. Since polarization itself is a type of electron localization, abundant localized electrons can help to increase the degree of polarization, and finally raise the dielectric constant. In the $\mathrm{Ba}^{\prime} \mathrm{iO}_{3} / \mathrm{SrTiO}_{3}$ modulated system, deposited structure of $\mathrm{BallO}_{3}$ as well as that of $\mathrm{SrTiO}_{3}$ are distorted and the distorted system becomes the origin of the higher dielectric constant. The experimental dielectric properties of the $\mathrm{BaliO}_{3} / \mathrm{SrTiO}_{3}$ modulated structure system will be shown shortly.

Acknowledgement. Authors acknowledge financial support from the Korean Science \& Engineering Foundation with the Grant \#R01-2002-00218-0.

\section{References}

1. (a) Jatje. B.: Roth. R. S.: Marzullo. S. I. Appl. Phys. 1954. 25. 809, (b) Jaffe. B.: Roth. R. S.: Marzullo. S. J. Res. Null. Bu: Stond. 1955, 55, 239

2. Ilayashi, S.: Shibata. I1: Waku, S. J. Flectron. Commm. Soc. Jn. 1975. 586.177 .185$.

3. L'az de Arauzo. C. A.: Cuchiaro. J. D.: McMillan. L. D.: Scoll. I. F. Fiture 1995. 374.627 .

4. Al-Sharcef. H. V.: Dimos. D.: Bovle. T. J.: Warren. W. L.: Tuttle. B. A. J. Appl. Phys tett 1996. 68.690 .

5. Dimos, D.: Al-Shareet, II, N.: Warren, W. I.: Tuttle. B. A. I Appl. Phs. Lett. 1996. so. 1682.

6. Moon. S.-Y.: Choi. K. S.: Jung. K. W.: Lee. H.: Jung. D. Bull. Aorean (hem. Soc. 2002. 23. 1463.

7. Unpublished document.

8. Tsurumi, T.: lchijkawa T.: I Iarigai, T.: Kakemoto. Il:- Wada S. 
Appl. Phws. 2002.91.2284.

9. LeMarrec. F.: Farhi. R.: El Marssi. M.: Delis. J. L.: Karkut. M. G. Phws. Rev B 2000. 61.6447.

10. Wang. C. L.: Sin, Y.: Wang, S. X: Zhong. W. L: Zhang. P. L. Phys. Letf. A 2000. 268. 117 .

11. Zhang. I: Yin. Z.: Zhang. M. S. Thim. Sol. Films 2000. 375. 255.

12. LeMarrec. F.: Farhi. R.: Dkhil. B.: Chevreul. J.: Karkut. M. G. J. Entopean Cer Soc. 2001. 21. 1615.

13. Nakagawa, O.: Shimuta, T: Makino, T.: Arai. S: Tabata, H.: Kawai, T. Article in press.

14. Rae, A. D.; Thompson, J. G.: Withers, R. L: Willis. A. C. Acta Cinstallogr. Sect B 1991. 17.174
15. Thompson. I. G.: Rae. A. D.: Withers. R. L.: Craig. D. C. Acta Crystallogr: Sect. B 1990. +6. 474 .

16. Rae A. D.: Thompsont. J. G.: Withers. R. L. Acta Cnstallogr Sect $B$ 1992, 48. 418.

17. Withers. R. L.: Thompson. J. G.: Rae. A. D. J. Solid State Chem 1991. 94, 404

18. Norton. M. G.: Carter. C. B. Scaming Hicrosc. 1992. 6. 385.

19. Tsai. C. T.: Atwater. H. A. Mater: Res Soc. Symp. Proc. 1992. 268. 127.

20. Ammeter. J. H.; Brgi, H.-B.: Thibeault, J; Hoffmann. R. $J$. Am Chem. Soc. 1978, 100. 3686.

21. Whangbo. M.-H; Hoftmann. R. I. Am. Chem. Soc. 1978, 100. 6093. 